\title{
APROTININ AND AORTIC CANNULA THROMBOSIS
}

\author{
Richard Gitter, MD, ${ }^{a}$ Peter Alivizatos, MD, ${ }^{a}$ John Capehart, MD, ${ }^{a}$ Michael Ramsay, MD, ${ }^{b}$ and G. Kimble Jett, MD, ${ }^{a}$ \\ Dallas, Tex.
}

Aprotinin has been advocated to reduce perioperative blood loss in patients undergoing cardiopulmonary bypass (CPB). ${ }^{1,2}$ Its effect on the coagulation cascade has been investigated by many researchers and its clinical effectiveness has been documented., ${ }^{3,4}$ However, the potential adverse sequelae of potent antifibrinolytic therapy has received less attention.

Thrombus formation has been reported with pulmonary artery catheters after aprotinin administration. ${ }^{5}$ Thrombus formation in the aortic outflow cannula, reported herein, represents a unique complication of antifibrinolytic therapy and merits attention.

Case report. A 64-year-old woman weighing $78 \mathrm{~kg}$, with end-stage congestive cardiomyopathy, underwent cardiac transplantation. Two million kallikrein inactivator units (KIU) of aprotinin was bolused intravenously before the initial skin incision, followed by a continuous infusion at $500,000 \mathrm{KIU} / \mathrm{hr}$. Additionally, another 2 million $\mathrm{KIU}$ of aprotinin was added to the extracorporeal circuit as a priming dose before institution of CPB. Before CPB, heparin $(4 \mathrm{mg} / \mathrm{kg}$ ) was administered and an activated clotting time (ACT) of 600 seconds obtained. (ACT was measured in celite test tubes in an automated device [Hemochron, International Technidyne Corp., Edison, N.J.]. ACTs during CPB ranged between 600 and 963 seconds.) After implantation of an 18-year-old donor heart, the patient had cardiac graft dysfunction resulting in cardiogenic shock and hypotension. Mechanical support with intraaortic balloon counterpulsation and aggressive inotropic support were instituted. The patient was weaned from CPB and protamine was administered.

After decannulation and observation in the operating room for 4 hours, the patient's cardiac hemodynamics worsened. She was therefore reheparinized $(4 \mathrm{mg} / \mathrm{kg})$ and, with the aid of CPB, ABIOMED BVS 5000 (ABIOMED Cardiovascular, Inc., Danvers, Mass.) biventricular assist devices (BVADs) were inserted. A new extracorporeal circuit and new cannulas were used. Aprotinin was not rebolused or added to the prime of the new CPB circuit,

From the Departments of Cardiothoracic Surgery and Anesthesia, ${ }^{b}$ Baylor University Medical Center, Dallas, Tex.

Received for publication Sept. 26, 1995; accepted for publication Oct. 20, 1995.

Address for reprints: G. Kimble Jett, MD, 1151 N. Buckner Blvd., No. 205, Dallas, TX 75218.

J Thorac Cardiovase Surg 1996;112:537-8

Copyright (C 1996 by Mosby-Year Book, Inc.

$0022-5223 / 96 \$ 5.00+0 \quad \mathbf{1 2 / 5 4 / 7 0 1 3 7}$ but the continuous infusion was continued throughout the period of observation and insertion of BVADs. The CPB time required for $\mathrm{BVAD}$ insertion was 105 minutes. ACTs measured during the second CPB time ranged from 984 to 1199 seconds. After separation from CPB and institution of biventricular support, the patient had stable hemodynamics. The aortic cannula was left in place for approximately 50 minutes after cessation of CPB for volume administration. Heparin was reversed with protamine and the continuous infusion of aprotinin was continued. The pump sucker was discontinued immediately with cessation of CPB and start of protamine administration. On removal of the aortic cannula, thrombus was noted in the lumen of the outflow cannula, which extended through the purse-string suture into the aorta. The thrombus was extracted from the aorta before the purse-string suture was secured. The venous cannula removed earlier had no thrombus.

The patient's hemodynamic status stabilized with biventricular support after the operation. The next morning she had a dilated and fixed left pupil and was neurologically unresponsive. A computed tomographic scan revealed a large infarct in the left hemisphere with generalized cerebral edema and tentorial herniation. Hemodynamic support was withdrawn at this point at the family's request. After termination of support, no thrombus was noted in the BVADs.

Discussion. Aprotinin is a potent nonspecific protease inhibitor that exerts its antifibrinolytic effect by kallikrein inhibition, thereby hindering progression of the complement and coagulation cascades. It is further believed to preserve platelet function by its effect on glycoprotein IB, the platelet membrane receptor for von Willebrand factor. ${ }^{1,2}$ High-dose infusion of this agent initiated before complex cardiac operations has been shown to reduce intraoperative and postoperative blood loss. This effect appears to be independent of systemic heparinization. ${ }^{3,4}$ Aprotinin has not been shown to be prothrombotic.

Outflow cannula thrombus after administration of aprotinin has not been previously described. Although early thrombus formation was reported with pulmonary artery catheters after aprotinin administration, ${ }^{5}$ there is a question of underheparinization in that report, because the ACT was only 497 seconds. Our patient had adequate anticoagulation. In addition, the pump sucker was immediately withdrawn from the field with protamine administration. New aortic and venous cannulas, as well as a new extracorporeal circuit, were used for BVAD insertion. We believe that leaving the aortic cannula for volume administration for a period of time after CPB contributed to stasis and thrombus formation within the aortic cannula. 
Earlier removal of the aortic cannula may have prevented this complication.

Thrombus formation, both microscopic and macroscopic, has the potential for disastrous complications in patients receiving antifibrinolytic therapy. The risk of thrombus formation may be increased with stasis of blood. We would therefore recommend early removal of intravascular catheters when antifibrinolytic therapy has been instituted.

\section{REFERENCES}

1. Harder MP, Eijsman L, Roozendaal KJ, van Oeveren W, Wildevuur RH: Aprotinin reduces intraoperative and postoperative blood loss in membrane oxygenator cardiopulmonary bypass. Ann Thorac Surg 1991;51:936-41.

2. Havel M., Teufelsbauer H, Knöbl P, Dalmatiner R, Jaksch P,
Zwölfer W, et al. Effect of intraoperative aprotinin administration on postoperative bleeding in patients undergoing cardiopulmonary bypass operation. J Thorac Cardiovasc Surg 1991;101:968-72.

3. Hardy JF, Desroaches J. Review article: Natural and synthetic antifibrinolytics in cardiac surgery. Can $\mathbf{J}$ Anaesth 1992;39: 353-65.

4. Bidstrup BP, Royston D, Sapsford RN, Taylor KM. Reduction in blood loss and blood use after cardiopulmonary bypass with high-dose aprotinin (Trasylol). J Thorac Cardiovasc Surg 1989;97:364-72.

5. Bohrer H, Fleischer F, Lang J, Vahl C. Early thrombus formation on pulmonary artery catheters in cardiac surgical patients receiving high dose aprotinin. J Cardiothorac Anesth 1990;4:222-6.

\section{RECURRENT THROMBOSIS OF BIVENTRICULAR-SUPPORT DEVICES ASSOCIATED WITH ACCELERATED INTRAVASCULAR COAGULATION AND INCREASED HEPARIN REQUIREMENTS}

George J. Despotis, MD, Vladimir Levine, MD, Alexander Alsoufiev, MD, Heinrich Joist, MD, PhD, Lawrence T. Goodnough, MD, and Michael Pasque, MD, St. Louis, Mo.

Thrombus formation in ventricular-assist devices has occurred despite apparently adequate anticoagulant therapy. The factors and mechanisms involved in the development of this potentially serious complication are poorly understood. We describe the case of a patient in whom multiple episodes of thrombosis developed in biventricular-support devices (BIVADs) used as a bridge to cardiac transplantation. These episodes were associated with accelerated intravascular coagulation and increased heparin requirements, which seemed to be favorably affected by administration of fresh-frozen plasma (FFP).

A 44-year-old white man came to our tertiary care institution for cardiac transplantation evaluation after a recent episode of congestive heart failure that was unresponsive to aggressive medical management. After an 8-year history of myocardial infarctions and progressive heart failure, he began a period of rapid deterioration 4 months before admission, at which time evaluation revealed endstage ischemic cardiomyopathy. Cardiac catheterization demonstrated global left ventricular hypokinesia with an ejection fraction of $7 \%$ and severe coronary artery dis-

From the Departments of Anesthesiology, Internal Medicine, Pathology, and Surgery, Washington University School of Medicine, and the Departments of Internal Medicine and Pathology, St. Louis University School of Medicine, St. Louis, Mo.

Supported in part by a research grant from ABIOMED Cardiovascular, Inc., Danvers, Mass.

Received for publication Aug. 7, 1995; accepted for publication Sept. 7, 1995.

J Thorac Cardiovase Surg 1996;112:538-40

Copyright (c) 1996 by Mosby-Year Book, Inc.

$0022-5223 / 96 \$ 5.00+0 \quad \mathbf{1 2 / 5 4} / \mathbf{6 9 2 5 4}$ ease; transthoracic echocardiography revealed moderately severe mitral and moderate tricuspid regurgitation. Previous management of his cardiac condition included inotropic support, afterload reduction, and diuresis. Laboratory evaluation showed elevated transaminase levels, reduced total protein level, reduced albumin level, and increased bilirubin level and prothrombin time, consistent with chronic, passive liver congestion.

On arrival, the patient was noted to be in severe congestive heart failure accompanied by tachycardia at 150 beats/min as a result of atrial flutter with a $2: 1$ conduction block. Initial treatment consisted of cardioversion to sinus rhythm followed by intravenous administration of nipride, dobutamine, and amrinone and subcutaneous injection of heparin (5000 U every 12 hours). The patient's condition worsened during the next several days, with development of cardiogenic shock (systolic blood pressure, 70 to $80 \mathrm{~mm} \mathrm{Hg}$; pulmonary artery wedge pressure, $38 \mathrm{~mm} \mathrm{Hg}$; cardiac index $<1.5$ ) despite large doses of dobutamine and amrinone necessitating bypass resuscitation on day 9 (Fig. 1). Subsequently, ABIOMED (ABIOMED Cardiovascular, Inc., Danvers, Mass.) biventricular support devices (BIVADs) were inserted as a bridge to transplantation. After insertion of the BIVADs, the patient had anticoagulation with a continuous infusion of heparin at 1800 to $2100 \mathrm{U} / \mathrm{hr}$ to maintain the celite activated clotting time (ACT) between 180 and 200 seconds. During days 9 through 19, a progressive increase in heparin requirements $(4000 \mathrm{U} / \mathrm{hr})$ was noted. On day 19 , clot formation in the BIVAD circuit necessitated emergency operative replacement of the BIVAD system (Fig. 1). Recurrent BIVAD thrombosis was noted on day 20 , necessitating a second replacement of the BIVAD system. In light of these events and a decrease in the platelet 